\title{
Investigating the Role of Multiple Intelligences in Determining Vocabulary Learning Strategies for L2 Learners
}

\author{
Mahsa Sistani ${ }^{1} \&$ Mahmood Hashemian ${ }^{2}$ \\ ${ }^{1}$ Department of Foreign Languages, Isfahan (Khorasgan) Branch, Islamic Azad University, Isfahan, Iran \\ ${ }^{2}$ Shahrekord University, Iran \\ Correspondence: Mahmood Hashemian, Shahrekord University, Iran. E-mail: m72h@hotman.com
}

Received: September 24, 2015 Accepted: May 20, 2016 Online Published: May 23, 2016

doi: $10.5539 /$ elt.v9n6p242

URL: http://dx.doi.org/10.5539/elt.v9n6p242

\begin{abstract}
This study, first, examined whether there was any relationship between Iranian L2 learners' vocabulary learning strategies (VLSs), on the one hand, and their multiple intelligences (MI) types, on the other hand. In so doing, it explored the extent to which MI would predict L2 learners' VLSs. To these ends, 40 L2 learners from Isfahan University of Technology in Isfahan participated in the study, and the following instruments were utilized to collect the data: the Oxford Placement Test (OPT) to gauge participants' proficiency level, the Multiple Intelligences Questionnaire (Mckenzie, 1999), and a vocabulary learning questionnaire based on the framework adopted from Schmitt's (1990). The strategies were divided into five categories: determination, memory, social, metacognitive, and cognitive. To analyze the data, Pearson correlation was applied to find out the relationship between the participants' intelligence categories and their preferred VLSs. Then, multiple regression analysis was run to indicate the significance of the specific VLSs in the participants' intelligences. Results revealed that there was a strong positive relationship between participants' intrapersonal intelligence and their tendency toward the cognitive and metacognitive strategies. Moreover, as participants' scores in their interpersonal intelligence test increased, they inclined toward the social strategies more. A potential positive and significant relationship between visual/spatial intelligence and memory strategies and also linguistic intelligence and determination strategies was also found out. Overall results revealed that the participants made a significant difference regarding their decisions for particular VLSs, as intrapersonal, interpersonal, linguistic, and visual learners predicted more specific and significant VLSs in comparison with other types of intelligences.
\end{abstract}

Keywords: Multiple intelligences (MI), Vocabulary learning strategies (VLSs), Proficiency level

\section{Introduction}

Learning an L2 is arguably one of the most cognitively challenging undertakings most people will go through in a life time, and many claim that learning the vocabulary of an L2 is likely the most challenging facet of becoming proficient in the L2 (Meara, 1995; Milton, 2009; Nation, 2001; Schmitt, 2000). One area of L2 vocabulary learning research that has been gaining attention in recent years to help explain the difficulties that some L2 learners encounter when learning vocabulary is the focus on learning strategies-vocabulary learning strategies (VLSs), in particular. As Schmitt (2000) argues, scholars' interest in VLSs stems from the movement to get away from a predominantly teacher-oriented pedagogical philosophy to a more learner-centered ideology that includes an interest in how learners themselves can manage their own L2 learning. Schmitt believes that it may be easier to apply learning strategies to vocabulary learning due to the relatively discrete nature of vocabulary learning as compared to more integrated language skills such as reading, writing, speaking, listening, and grammar.

As a significant part of L2 learning strategies, VLSs have received more attention since the late 1970s. The investigations also developed toward the process that L2 learners use to improve their skills and capabilities in an L2. Cunningsworth (1995) regards "VLSs as a powerful approach, which can be based on motivating L2 learners for dictionary skills, reflecting on effective techniques, and having sensitization to the system of vocabulary" (p. 38). According to Seal (as quoted in Celce-Murcia, 1991), "words are perceived as the building blocks upon which knowledge of the second language can be build" (p. 296). In the same direction, on the significance of vocabulary, Şener (2005) reiterated Wilkin's famous saying that without grammar, very little can be conveyed, without vocabulary nothing can be conveyed. 
Moreover, Nation (2001) argues that VLSs, as a strategy, would (a) involve choice to choose one appropriate among several strategies, (b) be complex, that is, there are various steps to learn, (c) demand knowledge and benefit from training, and (d) increase the efficiency of vocabulary learning, and vocabulary use and VLSs can also contribute to learning significantly. In a similar vein, Schmitt (1997) claims that VLSs can be any action that influenced the broad process of language learning strategies (LLSs) in an impressive way. Cameron (2001) defines VLSs as "actions that learners take to help themselves understand and remember vocabulary" (p. 92). Şener (2009) confirms that using or not using appropriate VLSs might be one of the important factors among other factors affecting successful or unsuccessful learning.

On the other side, by the advent of a significant shift from teaching to learning in L2 education, this change created an explosion of research and aimed at investigating different learner characteristics and language acquisition (Maftoon \& Najafi Sarem, 2012). Ellis (1985) stated that L2 learners are different in terms of their speed and performance in their L2 learning. Factors such as age, attitude, motivation, aptitude, cognitive styles, and intelligence can distinguish one individual from another in their ability to understand complex issues, to adapt effectively to the environment, to learn from experiences, and to engage in various reasoning (Gardner, 1983). Although there are many ways that L2 learners vary, intelligence is often considered as one of the most important predictors of L2 learning success (Ellis, 1985).

Multiple Intelligences (MI) theory is one of the most compelling approaches to L2 education. The ideas inherent in the MI theory were proposed in the early 1980s by Gardner in which he suggests that "the traditional notion of intelligence as measured by IQ testing is far too limited, and there are not just two ways to be intelligent, but many ways" (1983, p. 51). According to this theory, people are different in their different aspects of intelligence. This difference creates differences in people's performance on different tasks as well as different aspects of a special task.

The heart of MI theory relies on individualization and recognition of divergent abilities and personal differences. Gardner viewed "intelligence as the ability to solve problems, or to create products that are valued in one or more cultural setting" (Gardner \& Hatch, 1989, pp. 4-9). This definition challenged the traditional psychological view of intelligence as a single capacity that drives logical and mathematical thought. He asserts that the intelligences are eight types, and they are not meant to be reflections of emotions, personality or sensory acuity; rather, each of the intelligences is considered as computational capacity - the ability to process certain kinds of information in the process of solving a problem or fashioning a product.

The MI theory was proposed by Gardner in 1983. It provides a mean to understanding many ways in which human beings are intelligent, that is, how we actually process, learn, and remember information. The eight intelligences stated by Gardner (1999) are linguistic, logical/mathematical, spatial, kinesthetic/bodily, interpersonal, intrapersonal, visual/spatial, and naturalistic intelligences. Thus, this study tries to investigate the role of various intelligence types in determining VLSs among L2 learners.

\section{Literature Review}

Vocabulary knowledge is fundamental in L2 learning. L2 learners are aware of the importance of words, but they may be not cognizant of the concept of VLSs that can help them learn vocabulary successfully. Having concerned the demand to help L2 learners to find a way to go about learning vocabulary, Sokmen (1997) argues for helping L2 leaners to learn how to get vocabulary on their own; it is impossible for students to learn all the needed vocabulary in the classroom.

Schmitt's (1997) taxonomy is one of the most recent and comprehensive attempts to provide a classification scheme for a wide range of VLSs. According to Schmitt, "of the more established systems, the one developed by Oxford (1990) seemed best able to capture and organize the wide variety vocabulary learning strategies identified" (p. 205). As a result, Schmitt's taxonomy is organized by revising and expanding on Oxford's (1990) classification scheme. It aims at focusing on vocabulary learning and minimizing the potential overlaps in classification of strategies.

In addition, Gardner (1999) presented a new theory of intelligences called the MI theory. He sketched seven major intelligences: verbal-linguistic, logical-mathematical, visual-spatial, bodily-kinesthetic, musical, interpersonal, and intrapersonal. In the late 1990s, naturalistic was added, and other intelligences like existential, spiritual, and moral were under consideration to insert, but Gardner acknowledged only eight types of MI until now (Botelho, 2003).

On the road of the relationship between VLSs and MI, several studies were carried out; for instance, Razmjoo, Sahragard, and Sadri (2009) attempted to identify the relationship between MI, vocabulary learning knowledge, 
and VLSs among Iranian L2 learners. Senior students at Shiraz Azad University majoring in English language teaching participated in their study. The findings revealed that there was a relationship between MI and vocabulary learning knowledge. Furthermore, among the different types of intelligences, linguistic and natural intelligences made statistically significant contribution to the prediction of vocabulary learning knowledge. Moreover, stepwise multiple regression analysis confirmed the same result. Concerning the relationship between MI and vocabulary strategies, the results indicated that determination, social, and memory strategies had a significant relationship with several domains of MI.

Panahi (2012) examined the relationship between spatial intelligence and learning vocabulary. The results extracted from ANOVA showed that the groups with nonpictorial intelligence-based instruction and pictorial intelligence-based instruction performed differently on learning vocabulary and, according to the Pearson correlation, there was a significant relationship between spatial intelligence and learning vocabulary. Also, Skourdi, Damavand, Viyani, and Kashef (2012) attempted to nail down the relationship between linguistic intelligence and vocabulary knowledge among L2 learners. Gardner's MI questionnaire (linguistic section) and the revised version of Nation's 2,000 word-level test to receive the students' receptive and productive vocabulary knowledge were used. The results depicted a significant and positive relationship between linguistic intelligence and vocabulary knowledge, and it was reported as a good index of vocabulary learning.

As a more recent study in 2014, Khomeijani Farahani and Latifi Kalkhoran investigated the relationship between Iranian L2 learners' MI and incidental vocabulary learning. The results pointed out a significant relationship between the Iranian learners' MI and incidental vocabulary learning and also among the eight different types of intelligences. There was a significant relationship between naturalist and incidental vocabulary learning.

\section{Methodology}

\subsection{Participants}

For the present study, the participants were selected from 40 male and female L2 learners (i.e., 20 females and 20 males), whose age ranged from 15-46 and who participated in the study from Isfahan University of Technology. The participants were from intermediate proficiency levels in this research, the reason of which was that such participants were more competent to identify the concept of VLSs, and the diction of the questionnaire was easier to comprehend for such learners.

\subsection{Materials}

Three instruments were employed: the Oxford Placement Test (OPT; Allan, 1992) with appropriate measures of reliability and validity to determine the proficiency level of the participants prior to study; the OPT consisted of 100 items that assessed the grammatical knowledge of the participants.

The Multiple Intelligence Survey developed by McKenzie (1999) was used to check the different types of intelligences to which the participants belonged. The survey contained nine major sections regarding intelligence types (i.e., naturalistic, musical, logical/mathematical, existential, interpersonal, bodily/kinesthetic, verbal/linguistic, intrapersonal, and visual/spatial); each section contained 10 statements that the participants had to mark each part which was true regarding their personality; it is also worth mentioning that more than one absolute intelligence was possible for the participants.

The last instrument was a vocabulary learning questionnaire based on the framework adopted from Schmitt's (1990). The strategies were divided into five categories: determination, memory, social, metacognitive, and cognitive.

\subsection{Procedure}

The three instruments (i.e., the OPT, the MI questionnaire, and the VLSs questionnaire) were administered to the participants in three consecutive weeks. In the first step, through administering the OPT, the homogeneous entry behavior of the participants in terms of proficiency was ensured. The participants who scored lower than $50 \%$ of the total possible score were excluded from the study regarding their level of proficiency. After selecting 40 intermediate participants, the MI questionnaire was distributed to identify their intelligence profiles. The last step was dedicated to giving out the VLSs questionnaire to figure out the participants' tendencies regarding different VLSs.

Furthermore, in an attempt to check and ensure the usefulness, clarity, relevance, format, reliability, and time allotment of the items included in the VLSs questionnaire, 10 participants with similar proficiency levels to the main participants of the study attended at the phase of pilot-testing of the students' preferred types of VLSs Questionnaire. 


\section{Result}

In order to find out the potential relationship between these different types of intelligences and the main subcategories of VLSs types, Pearson correlation was run (see Table 1):

Table 1. Pearson correlation between different types of VLSs strategies and intelligences

\begin{tabular}{llllll}
\hline & Determination & Memory & Social & Metacognitive & Cognitive \\
\hline \multirow{2}{*}{ Naturalist } & -0.140 & -0.016 & 0.165 & 0.142 & 0.277 \\
Musical & $(0.389)$ & $(0.923)$ & $(0.310)$ & $(0.381)$ & $(0.083)$ \\
Interpersonal & 0.190 & 0.025 & -0.023 & -0.125 & 0.007 \\
& $(0.241)$ & $(0.878)$ & $(0.887)$ & $(0.441)$ & $(0.968)$ \\
Existential & -0.021 & 0.217 & 0.503 & 0.293 & 0.140 \\
& $(0.895)$ & $(0.179)$ & $(0.001)$ & $(0.066)$ & $(0.389)$ \\
Logical & 0.189 & 0.001 & 0.120 & 0.178 & -0.022 \\
& $(0.244)$ & $(0.997)$ & $(0.462)$ & $(0.272)$ & $(0.892)$ \\
Kinesthetic & -0.142 & 0.198 & 0.236 & 0.018 & 0.169 \\
& $(0.381)$ & $(0.220)$ & $(0.143)$ & $(0.912)$ & $(0.298)$ \\
Linguistic & -0.250 & 0.296 & 0.047 & 0.167 & 0.224 \\
& $(0.120)$ & $(0.064)$ & $(0.775)$ & $(0.302)$ & $(0.165)$ \\
Intrapersonal & 0.382 & 0.121 & -0.177 & -0.056 & 0.186 \\
& $(0.015)$ & $(0.458)$ & $(0.274)$ & $(0.731)$ & $(0.250)$ \\
Visual & 0.061 & 0.079 & 0.069 & 0.484 & 0.557 \\
& $(0.708)$ & $(0.629)$ & $(0.672)$ & $(0.002)$ & $(0.000)$ \\
& -0.201 & 0.327 & 0.243 & -0.008 & -0.110 \\
Note $p<.05(2-1 a)$ & $(0.214)$ & $(0.131)$ & $(0.962)$ & $(0.499)$ \\
\hline
\end{tabular}

Note. ${ }^{*} p<.05$ (2-tailed).

As Table 1 reveals, the highest statistical significant correlations were found between the intrapersonal intelligence and cognitive and metacognitive strategies ( $r=0.48, p<0.05 ; r=0.55, p<0.05$, respectively), as well as the interpersonal intelligence and social strategies $(r=0.5, p<0.05)$. Moreover, a possible positive significant relationship between linguistic and visual intelligences and determination and memory strategies was observed $(r=0.38, p<0.05 ; r=0.32, p<0.05$ in order), whereas the lowest relationship existed between the other types of intelligences. In sum, the cognitive, metacognitive, and social strategies showed significant correlations with intrapersonal and interpersonal intelligences. Also, linguistic intelligence showed the highest correlations with determination and visual intelligence with memory strategies.

To investigate which intelligence type could predict the participants' vocabulary strategy use, a series of multiple regressions were conducted. As Table 2 illustrates, linguistic intelligence had the largest Beta value, hence making the strongest unique contribution to the determination VLSs use. The other eight types of intelligences did not show a significant effect on determination, and linguistic intelligence was shown as the unique significant effective intelligence on using the determination strategy in this study. 
Table 2. Regression analysis on the effect of intelligences on determinism

\begin{tabular}{llllllll}
\hline & Beta & Std. Error & $\begin{array}{l}\text { Standardized coefficients } \\
\text { Beta }\end{array}$ & $t$ & Sig. & $\begin{array}{l}\text { Partial } \\
\text { Correlation }\end{array}$ & V IF \\
\hline Naturalist & -0.003 & 0.009 & -0.066 & -0.375 & 0.711 & -0.068 & 1.400 \\
Musical & 0.013 & 0.008 & 0.260 & 1.501 & 0.144 & 0.264 & 1.339 \\
Interpersonal & 0.000 & 0.007 & -0.010 & -0.056 & 0.956 & -0.010 & 1.289 \\
Existential & 0.010 & 0.007 & 0.226 & 1.289 & 0.207 & 0.229 & 1.364 \\
Logical & -0.006 & 0.008 & -0.134 & -0.818 & 0.420 & -0.148 & 1.200 \\
Kinesthetic & -0.004 & 0.007 & -0.093 & -0.536 & 0.596 & -0.097 & 1.330 \\
Linguistic & 0.018 & 0.007 & 0.418 & 2.549 & 0.016 & 0.422 & 1.197 \\
Intrapersonal & 0.004 & 0.007 & 0.082 & 0.508 & 0.615 & 0.092 & 1.165 \\
Visual & -0.003 & 0.006 & -0.084 & -0.511 & 0.613 & -0.093 & 1.215 \\
\hline
\end{tabular}

Table 3. Regression analysis on the effect of intelligences on memory

\begin{tabular}{llllllll}
\hline & Beta & Std. Error & $\begin{array}{l}\text { Standardized } \\
\text { Beta }\end{array}$ & $t$ & Sig. & $\begin{array}{l}\text { Partial } \\
\text { Correlation }\end{array}$ & VIF \\
\hline Naturalist & 0.001 & 0.007 & 0.001 & 0.006 & 0.995 & 0.001 & 1.400 \\
Musical & 0.008 & 0.007 & 0.189 & 1.164 & 0.254 & 0.208 & 1.339 \\
Interpersonal & 0.011 & 0.006 & 0.306 & 1.917 & 0.065 & 0.330 & 1.289 \\
Existential & 0.000 & 0.006 & 0.005 & 0.030 & 0.976 & 0.006 & 1.364 \\
Logical & 0.006 & 0.006 & 0.143 & 0.928 & 0.361 & 0.167 & 1.200 \\
Kinesthetic & 0.008 & 0.006 & 0.190 & 1.334 & 0.193 & 0.205 & 1.330 \\
Linguistic & 0.013 & 0.006 & 0.336 & 2.180 & 0.037 & 0.370 & 1.197 \\
Intrapersonal & 0.011 & 0.006 & 0.269 & 1.773 & 0.086 & 0.308 & 1.165 \\
Visual & 0.014 & 0.005 & 0.438 & 2.823 & 0.008 & 0.458 & 1.215 \\
\hline
\end{tabular}

According to Table 3, linguistic and visual intelligences had significant effects on using the memory strategy. The values of 0.33 and 0.43 for the standardized coefficients of linguistic and visual intelligences respectively indicate a positive relationship between these two intelligences and the memory strategy in comparison with other types of intelligences. In addition, it can be inferred from these values that visual intelligence had a relatively stronger effect on using memory strategy in comparison to linguistic intelligence.

Table 4. Regression analysis on the effect of intelligences on social

\begin{tabular}{llllllll}
\hline & Beta & Std. Error & $\begin{array}{l}\text { Standardized } \\
\text { Beta }\end{array}$ & $t$ & Sig. & $\begin{array}{l}\text { Partial } \\
\text { Correlation }\end{array}$ & VIF \\
\hline Naturalist & 0.014 & 0.010 & 0.376 & 1.401 & 0.169 & 0.405 & 1.400 \\
Musical & -0.007 & 0.010 & -0.114 & -0.752 & 0.458 & -0.136 & 1.339 \\
Interpersonal & 0.028 & 0.008 & 0.545 & 3.666 & 0.001 & 0.556 & 1.289 \\
Existential & 0.006 & 0.008 & 0.108 & 0.703 & 0.487 & 0.127 & 1.364 \\
Logical & 0.009 & 0.009 & 0.157 & 1.097 & 0.282 & 0.196 & 1.200 \\
Kinesthetic & -0.004 & 0.008 & -0.066 & -0.439 & 0.664 & -0.080 & 1.330 \\
Linguistic & 0.002 & 0.008 & 0.035 & 0.242 & 0.810 & 0.044 & 1.197 \\
Intrapersonal & 0.013 & 0.008 & 0.222 & 1.573 & 0.126 & 0.276 & 1.165 \\
Visual & 0.007 & 0.006 & 0.112 & 1.167 & 0.250 & 0.228 & 1.215 \\
\hline
\end{tabular}


Table 4 displays the results of parameter estimation of the regression model. According to this table, interpersonal intelligence had a significant effect on the social strategy. The value of 0.545 for the standardized coefficient of this variable indicates a relatively strong positive relationship between interpersonal intelligence and the social strategy while controlling for other types of intelligences. Interpersonal intelligence was the unique significant intelligence predicting the social strategy in this study.

Table 5. Regression analysis on the effect of intelligences on metacognitive

\begin{tabular}{llllllll}
\hline & Beta & Std. Error & $\begin{array}{l}\text { Standardized } \\
\text { Beta }\end{array}$ & $t$ & Sig. & $\begin{array}{l}\text { Partial } \\
\text { Correlation }\end{array}$ & VIF \\
\hline Naturalist & 0.017 & 0.010 & 0.264 & 1.717 & 0.096 & 0.299 & 1.400 \\
Musical & -0.006 & 0.010 & -0.090 & -0.596 & 0.555 & -0.108 & 1.339 \\
Interpersonal & 0.014 & 0.008 & 0.267 & 1.747 & 0.089 & 0.332 & 1.289 \\
Existential & 0.012 & 0.008 & 0.210 & 1.386 & 0.176 & 0.245 & 1.364 \\
Logical & 0.005 & 0.009 & 0.082 & 0.575 & 0.569 & 0.104 & 1.200 \\
Kinesthetic & 0.006 & 0.008 & 0.113 & 0.754 & 0.457 & 0.136 & 1.330 \\
Linguistic & 0.007 & 0.008 & 0.130 & 0.916 & 0.367 & 0.165 & 1.197 \\
Intrapersonal & 0.034 & 0.008 & 0.581 & 4.139 & 0.000 & 0.603 & 1.165 \\
Visual & 0.006 & 0.006 & 0.141 & 0.985 & 0.333 & 0.177 & 1.215 \\
\hline
\end{tabular}

According to Table 5, intrapersonal intelligence had a significant effect on the metacognitive strategy. The value of 0.581 for the standardized coefficient of this variable indicates a relatively strong positive relationship between intrapersonal intelligence and using metacognitive strategy rather than the other types of intelligences.

Table 6. Regression analysis on the effect of intelligences on cognitive

\begin{tabular}{llllllll}
\hline & Beta & Std. Error & $\begin{array}{l}\text { Standardized } \\
\text { Beta }\end{array}$ & $t$ & Sig. & $\begin{array}{l}\text { Partial } \\
\text { Correlation }\end{array}$ & VIF \\
\hline Naturalist & 0.008 & 0.007 & 0.125 & 1.143 & 0.260 & 0.209 & 1.400 \\
Musical & 0.006 & 0.007 & 0.102 & 0.842 & 0.407 & 0.152 & 1.339 \\
Interpersonal & 0.011 & 0.006 & 0.219 & 1.833 & 0.074 & 0.345 & 1.289 \\
Existential & 0.007 & 0.006 & 0.132 & 1.08 & 0.289 & 0.193 & 1.364 \\
Logical & 0.011 & 0.007 & 0.294 & 1.571 & 0.124 & 0.325 & 1.200 \\
Kinesthetic & 0.01 & 0.006 & 0.194 & 1.605 & 0.119 & 0.281 & 1.330 \\
Linguistic & 0.012 & 0.008 & 0.274 & 1.5 & 0.142 & 0.507 & 1.197 \\
Intrapersonal & 0.04 & 0.006 & 0.631 & 6.443 & 0.001 & 0.762 & 1.165 \\
Visual & 0.005 & 0.005 & 0.127 & 1.102 & 0.279 & 0.197 & 1.215 \\
\hline
\end{tabular}

Table 6 demonstrates parameter estimation results of the regression model. According to this table, intrapersonal intelligence had a significant effect on the cognitive strategy, too. The value of 0.631 for the standardized coefficient of this variable indicates a relatively strong positive relationship between intrapersonal intelligence and employing the metacognitive strategy.

\section{Discussion}

The findings are consistent with several studies as they adhered the relationship between MI and reading, writing, communication, learning strategies, and vocabulary knowledge and learning, particularly for interpersonal, intrapersonal, visual, and linguistic intelligences of the participants (i.e., Ahmadian \& Hosseini, 2012; 
Hashemian \& Adibpour, 2012; Marefat, 2007; Moheb \& Bagheri, 2013; Rahimi, Mirzaei, \& Heidari, 2012; Razmjoo, Sahragard, \& Sadri, 2009; Shangarffam \& Zand, 2012).

In the present study, the intrapersonal participants perceived the metacognitive and cognitive strategies as the most significantly used strategy type. Metacognitive strategies include "reflective action-tactics" about what an L2 student does to better inform "choices about where, when, and how to deal with the processing elements" in learning (Bartlett et al., 2012, p. 7). And as such, they can be considered as an opportunity to provide L2 students with knowledge that makes them manage their own learning and "empowers them to be inquisitive and zealous in their pursuits" (Paris \& Winograd, 1990, p. 22).

There might be several reasons for the reported significant relationship and the use of metacognitive strategies, even though care should be taken to avoid broad generalization about the results from the self-report questionnaire. The high use of metacognitive strategies might partly derive from the fact that, to use Liyanage, Bartlett, Birch, and Tao's (2012) terms, "outside the classroom, L2 learners are operating metacognitively to manipulate the successful joint maintenance of meaning" (p. 13). Part of learning takes place outside the classroom; students need to choose what works in a context where a teacher is no longer exercising a controlling influence and there is little access to native speakers of the $\mathrm{L} 2$.

Thus, the justification for intrapersonal intelligence for metacognitive and cognitive VLSs is the point that intrapersonal intelligence is connected with self-awareness and consciousness, and these learners utilize cognitive and metacognitive strategies to manipulate different strategies for efficient vocabulary learning. The progressive sense of evaluation, analysis, and reflection in intrapersonal learners is likely to intrigue them to analyze the parts of vocabulary for better memorization and using various softwares including vocabulary tests to evaluate their knowledge of vocabulary constantly. Also, in their case of self-reflection, they are persistently dealing with several strategies to improve their potential weaknesses and deficits regarding vocabulary knowledge and lexicon size.

Furthermore, the results showed that the high level of the participants' MI was significantly and positively associated with the high level of their VLSs. The above finding indicates that L2 learners' efficient use of VLSs can be tightly linked to particular types of their intelligence. Such a finding appears logical because, as Akbari and Hosseini (2008) argue, many aspects of MI correspond to some aspects of VLSs use, such as communication skills (linguistic, interpersonal), metacognition (intrapersonal).

Additionally, linguistic and intrapersonal intelligences had the highest correlation with determination and metacognitive strategies. Also, the correlation between intrapersonal intelligence and the cognitive strategies was the highest. The above results are justified because linguistic intelligence is "the understanding of phonology, syntax, and semantics of language, and its pragmatic uses to convince others of a course of actions, help one to remember information, explain or communicate knowledge, and reflect upon language itself" (Armstrong, 2003, pp. 13-14), so L2 learners are inclined to use cognates, flashcards, and dictionaries in order to analyze and memorize vocabularies. Similarly, intrapersonal intelligence helps individuals to evaluate, or critique information, how to analyze, do certain L2 learning tasks, and reflect on the L2 learning process. Thus, intrapersonal intelligence can be associated with cognitive and metacognitive strategies, particularly the cognitive ones that concern analyzing and reasoning with the goal of improving their L2 knowledge.

Upon looking for social strategies, interpersonal intelligence predicted this strategy more significantly than others. The potential reasons underlying this refer to the point that this intelligence is majorly concerned with the perception of other people's feelings, and it is the ability to understand other people's motivations, intentions, desires, and interactions with others. Moreover, as far as interpersonal individuals are usually extroverts and they typically learn best by working with others and often enjoy discussion and debate, they tend to collaborate with their peers and teachers in a group to ask for synonyms and definitions for those vocabularies that they encounter problems with.

As far as visual intelligence is mainly concerned with employing visual imagery, graphic representations, drawings, and illustrations, a potential significant relationship between visual intelligence and memory strategies is justifiable. The result of this study is in line with Panahi (2012) as he found a significant relationship between spatial intelligence and learning vocabulary.

\section{Conclusion}

As noted in the Discussion section, the first purpose of this study was to research about the potential relationship between the VLSs that L2 learners prefer in their classroom activities and their different MI types. The results gleaned from the Pearson product correlation indicated that there was a positive and significant relationship 
between the intrapersonal intelligence of the participants and their tendency toward the cognitive and metacognitive strategies. Moreover, as the participants' scores in their interpersonal intelligence test increased, they inclined toward the social strategies more (i.e., talking to native speakers, asking teachers for paraphrase and giving synonyms, studying words in panel and group activities, etc.). A potential positive and significant relationship between visual/spatial intelligence and the memory strategies as well as linguistic intelligence and the determination strategies was found out.

The second aim of this study was to explore whether various types of MIs predict more different and significant VLSs among L2 learners. The overall results revealed that the participants made a significant difference regarding their decisions for particular VLSs, as intrapersonal, interpersonal, linguistic and visual learners predicted more specific and significant VLSs in comparison with other types of intelligences.

The findings draw attention that not only can L2 knowledge but also various types of MI be significantly related to L2 performance. Additionally, it could be deduced that L2 teacher education programs should address the significance of this issue and inform L2 teachers about the potential role of intelligence in L2 performance. Thus, L2 teacher educators should expand their knowledge of the interplay of such MIs with L2 learning through holding relevant classes/workshops and make them cognizant of some practical considerations to enhance the quality of their L2 instruction.

If MI-based instruction is used in L2 classroom, materials can be taught "through a variety of well-woven and integrated intelligences in lessons in the classroom" (Chen, 2005, p. 151). MI-based curriculum in L2 teaching can account for some contextual and cultural differences L2 teachers may encounter in teaching L2 students with different social or cultural backgrounds and preferences. Furthermore, given that most L2 students are generally assumed to be passive in Iranian educational settings (Shirani Bidabadi \& Yamat, 2010), strategies-based instruction integrated with MI-based curriculum can be useful; Iranian L2 teachers should take into account L2 learners' favored strategies in their teaching and, consequently, suggest activities designed to help them to make maximum use of their VLSs.

Like any other research, this study is not without limitations. First, sample size was not large enough to generalize the findings. The second drawback of this study deals with the participants' gender. The data were collected from both male and female L2 learners, and the effect of gender on the study results was not monitored. The third limitation is related to the fact that the participants came from merely the language centers in Isfahan; as such, they were not representative of all the Iranian L2 learners who study at different cities of Iran. The final shortcoming is that the participants belonged to different sociocultural backgrounds. In fact, sociocultural factors could particularly have influenced the participants' MI profiles.

\section{References}

Akbari, R., \& Hosseini, K. (2008). Multiple intelligences and language learning strategies: Investigating possible relations. System: An International Journal of Educational Technology and Applied Linguistics, 36(2), 141-155. http://dx.doi.org/10.1016/j.system.2007.09.008

Armstrong, T. (2003). The multiple intelligences of reading and writing: Making the words come alive. Alexandria, VA: ASCD.

Armstrong, T. (2009). Multiple intelligences in the classroom (3rd ed.).Virginia: ASCD.

Botelho, M. (2003). Multiple intelligences theory in English language teaching: An analysis of current textbooks, materials, and teachers 'perceptions. Unpublished master's thesis, Ohio University.

Cameron, L. (2001). Teaching languages to children. Cambridge: Cambridge University.

Celce-Murcia, M. (1991). Teaching English as a second or foreign language (2nd ed.). United States: Newbury House.

Chen, S. (2005). Cooperative learning, multiple intelligences and proficiency: Application in college English language teaching and learning. Unpublished doctoral dissertation, Australian Catholic University, Australia.

Cunningsworth, A. (1995). Choosing your course book. Oxford: Heinemann.

Ellis, R. (1985). Understanding second language acquisition. Oxford: Oxford University.

Gardner, H. (1993). Multiple intelligences: The theory in practice. New York: Basic Books.

Gardner, H. (1999). Intelligence reframed multiple intelligences for the 21st century. New York: Basic Books.

Hashemian, M., \& Adibpour, M. (2012). Relationship between Iranian L2 learners' multiple intelligences and 
language learning strategies. RALs, 3(1), 26-43.

Khomeijani Farahani, A. A., \& Latifi Kalkhoran, E. (2014). The relationship between incidental vocabulary learning and multiple intelligences of Iranian EFL learners. Theory and Practice in Language Studies, 4(1), 58-64. http://dx.doi.org/10.4304/tpls.4.1.58-64

Liyanage, I., Bartlett, B., Birch, G., \& Tao, T. (2012). "To be or not to be" metacognitive: Learning EFL strategically. Electronic Journal of Foreign Language Teaching, 9(1), 5-25.

Maftoon, P., \& Najafi Sarem, S. (2012). The realization of Gardner's multiple intelligences (MI) theory in second language acquisition (SLA). Journal of Language Teaching and Research, 3(6), 1233-1241. http://dx.doi.org/10.4304/jltr.3.6.1233-1241

Marefat, F. (2007). Multiple intelligences: Voices from an EFL writing class. Pazhuhesh-e Zabanha-ye Khareji, $32,145-162$.

McKenzie, W. (1999). Multiple intelligences survey. Retrieved October 9, 2014, from the World Wide Web: http://surfaquarium.com/MI/MIInvent.htm

Meara, P. (1996). The dimensions of lexical competence. In G. Brown, K. Malmkjaer, \& J. Williams (Eds.), Performance and competence in secondary language acquisition (pp. 35-53). Cambridge: Cambridge University Press.

Milton, J. (2009). Measuring second language vocabulary acquisition. Bristol, UK: Multilingual Matters. http://dx.doi.org/10.1057/9780230242258_12

Moheb, N., \& Bagheri, M. (2013). Relationship between multiple intelligences and writing strategies. Journal of Language Teaching and Research, 4(4), 777-784. http://dx.doi.org/10.4304/jltr.4.4.777-784

Nation, I. S. P. (2001). Learning vocabulary in another language. Cambridge: Cambridge University Press. http://dx.doi.org/10.1017/CBO9781139524759

Oxford, R. (1990). Language learning strategies: What every teacher should know. Boston: Heinle \& Heinle.

Panahi, A. (2012). From psychology of intelligence to the pedagogy of multiple-intelligences: Impact of spatial intelligence-based instruction on the vocabulary performance of EFL learners. Iranian EFL Journal, 8(2), 128-142.

Paris, S. G., \& Winograd, P. (1990). How metacognition can promote academic learning and instruction. In B. F. Jones, \& L. Idol (Eds.), Dimensions of thinking and cognitive instruction (pp. 15-51). Hillsdale, NJ: Erbaum.

Rahimi, M., Mirzaei, A., \& Heidari, N. (2012). How do successful EFL readers bridge between multiple intelligences and reading strategies? World Applied Sciences Journal, 17(9), 1134-1142.

Razmjoo, S. A., Sahragard, R., \& Sadri, M. (2009). On the relationship between multiple intelligences, vocabulary learning knowledge and vocabulary learning strategies among the Iranian EFL learners. Iranian EFL Journal, 3, 82-110.

Schmitt, N. (1997). Vocabulary learning strategies. In N. Schmitt \& M. McCarthy (Eds.), Vocabulary: Description, acquisition, and pedagogy (pp. 303-320). Cambridge: Cambridge University Press.

Schmitt, N. (2000). Vocabulary in language teaching. New York: Cambridge University Press.

Şener, S. (2005). The relationship between vocabulary learning strategies and vocabulary size of Turkish EFL students. Retrieved from http: //yadem.Com.Edu.Tr/3rdELTkonf/spkrsener.htm

Şener, S. (2009). The relationship between vocabulary learning strategies and vocabulary size of Turkish EFL students. Retrieved May 30, 2014, from the World Wide Web: http://yadem.comu.edu.tr/ 3rdeltkonf/spkr_sabriye_sener.htm

Shangarffam, N., \& Zand, A. (2012). Iranian foreign language learners' multiple intelligences and their use of oral communication strategies, The Iranian EFL Journal, 8(4), 310-328.

Shirani Bidabadi, F., \& Yamat, H. (2010). Learning style preferences by Iranian EFL freshman university students. Procedia - Social and Behavioral Sciences, 7, 219-226. http://dx.doi.org/10.1016/j.sbspro.2010.10.031

Skourdi, S., Damavand, A., Viyani, A., \& K, S.H. (2012). On the relationship between linguistic intelligence and vocabulary knowledge among Iranian EFL learners. Iranian EFL Journal, 8(6), 289-303. 
Sokmen, A. (1997). Current trends in teaching second language vocabulary. In N. Schmitt, \& M. McCarthy (Eds.), Vocabulary: Description, acquisition, and pedagogy (pp. 237-257). Cambridge: Cambridge University.

\section{Copyrights}

Copyright for this article is retained by the author(s), with first publication rights granted to the journal.

This is an open-access article distributed under the terms and conditions of the Creative Commons Attribution license (http://creativecommons.org/licenses/by/3.0/). 